\title{
Silty Clay Stabilization Using Metakaolin-Based Geopolymer Binder
}

\author{
Shengnian Wang ${ }^{1 *}$, Jun $\mathrm{Su}^{1}$, Zhijian $\mathrm{Wu}^{1 *}$, Wei $\mathrm{Ma}^{2}$, Yue $\mathrm{Li}^{3}$ and Honglei Hui ${ }^{1}$ \\ ${ }^{1}$ College of Transportation Science and Engineering, Nanjing Tech University, Nanjing, China, ${ }^{2}$ State Key Laboratory of Frozen \\ Soil Engineering, Cold and Arid Regions Environmental and Engineering Research Institute, Chinese Academy of Sciences, \\ Lanzhou, China, ${ }^{3}$ State Key Laboratory of Safety and Health for Metal Mines, Sinosteel Maanshan Institute of Mining Research, \\ Co., Ltd., Maanshan, China
}

OPEN ACCESS

Edited by:

Qingxiang Meng,

Hohai University, China

Reviewed by:

Jun $Y u$,

Nantong University, China

Sultan Akhtar

Imam Abdulrahman Bin Faisal

University, Saudi Arabia

${ }^{*}$ Correspondence:

Shengnian Wang

shengnian.wang@njtecj.edu.cn

Zhijian Wu

zhijian@njtech.edu.cn

Specialty section:

This article was submitted to Interdisciplinary Physics,

a section of the journal

Frontiers in Physics

Received: 02 September 2021

Accepted: 15 October 2021

Published: 26 November 2021

Citation:

Wang S, Su J, Wu Z, Ma W, Li Y and Hui H (2021) Silty Clay Stabilization

Using Metakaolin-Based

Geopolymer Binder.

Front. Phys. 9:769786.

doi: 10.3389/fphy.2021.769786
Geopolymer binders are adjudged as the latest wave of sustainable alkali-activated materials for soil stabilization due to their excellent bonding properties. This study applied metakaolin as a precursor for synthesizing the geopolymer binder by employing the mixture of quicklime and sodium bicarbonate as an alkali activator. The optimal mass mixing ratio of the alkali activator, metakaolin, and silty clay was determined by unconfined compression tests. The stabilization mechanisms of the geopolymer binder were measured by $\mathrm{x}$-ray diffraction and Fourier transform infrared spectroscopy. The microstructural characteristics of the geopolymer-stabilized silty clay were observed by scanning electron microscopy with an energy dispersive $x$-ray spectroscopy and mercury intrusion porosimetry test for understanding the strengthening mechanism of the silty clay after the treatment. Results indicate that the optimal mass mixing ratio of the alkali activator, metakaolin, and silty clay is $1: 2: 17$, and the unconfined compressive strength of the geopolymer-stabilized silty clay reaches the maximum value of $0.85 \mathrm{MPa}$ with adding $15 \mathrm{wt} \%$ of the geopolymer binder. Diffraction patterns show an insufficient polymerization of the geopolymer binder in the silty clay in the early days but a rapid synthesis of aluminosilicate gels after that. The new asymmetrical stretching vibration peaks signified the formation of aluminosilicate networks and are responsible for the strength improvement of the silty clay. Microstructural analyses further confirm the formation of aluminosilicate gels and their positive impacts on the structure of the silty clay over curing age.

Keywords: soil stabilization, geopolymer, alkali-activation, mixing ratio, microstructural characteristics

\section{INTRODUCTION}

Chemical stabilization of problematic soils is a traditional but cost-effective technique for enhancing soil properties by incorporating various industrial-based chemical binders into soils, such as ordinary Portland cement (OPC), quicklime ( $\mathrm{CaO})$, fly ash (FA), and polymer, to improve the interfacial bonding effect of particles for satisfying the normative objectives sought by engineering practices [1, 2]. However, the product of $\mathrm{CaO}$ hydration would result in significant dry shrinkage and crack and thus not be allowed to use on high-class road bases [3]. The OPC has been proven suitable for improving almost all kinds of soils [4] but possesses the disadvantages of low tensile and flexural strengths. The remarkable dimension shrinkage and crack will be caused by water evaporation during the hardening process once the dosage of cement in soils is excessive [5]. Besides, the overdependence on cement and quicklime will also give rise to many environmental concerns, 
including $\mathrm{CO}_{2}$ emission, energy consumption, and dust generation [6]. All these drawbacks thus continuously inspire developments in new alternative binders that possess low environmental footprints and without compromising soil stabilization capabilities.

Geopolymer binder (GB) is an inorganic alkali-activated material touted for high strength and durability, low energy consumption, and low $\mathrm{CO}_{2}$ emission [7, 8]. Many studies indicated that the raw materials of GB could be metakaolin $(\mathrm{MK})$, fly ash (FA), glass waste $(\mathrm{GW})$, red mud (RM), and combinations of two or more of these materials, and the alkali activator (AA) could be $\mathrm{R}_{\mathrm{x}} \mathrm{OH}, \mathrm{R}_{\mathrm{x}} \mathrm{CO}_{3}, \mathrm{R}_{\mathrm{x}} \mathrm{HCO}_{3}, \mathrm{R}_{\mathrm{x}} \mathrm{O} \cdot(\mathrm{n}) \mathrm{SiO}_{2}$, or other alkaline metal oxides $\left(\mathrm{R}_{\mathrm{x}} \mathrm{O}\right)$ in which $R_{x}$ represents an alkaline ion, such as $\mathrm{Na}^{+}, \mathrm{K}^{+}, \mathrm{Li}^{+}$, or $\mathrm{Ca}^{2+}$ [9-11]. Despite the fact that properties of different raw materials and alkaliactivated conditions could affect the dissolution process and subsequent reaction directly, resulting in GB exhibiting a wide variety of physical and mechanical properties, the fundamental chemical and structural characteristics derived from coupled alkali-mediated dissolution and precipitation reactions are the same [9].

$$
\begin{gathered}
\left(\mathrm{SiO}_{2} \cdot \mathrm{Al}_{2} \mathrm{O}_{3}\right)_{n}+\mathrm{H}_{2} \mathrm{O}+\mathrm{OH}^{-} \rightarrow\left[\mathrm{SiO}_{2}(\mathrm{OH})_{2}\right]^{2-} \\
+\left[\mathrm{Al}(\mathrm{OH})_{4}\right]^{-} \stackrel{-\mathrm{H}_{2} \mathrm{O}}{\longrightarrow}(\underset{\substack{\mathrm{I} \\
\mathrm{O}}}{\mathrm{Si}}-\mathrm{O}-\underset{\mathrm{I}}{\mathrm{A}} \mathrm{A}-\mathrm{O}-)
\end{gathered}
$$

Some researchers paid more attention to the mixing ratio of $\mathrm{GB}$ and reaction products. Chen et al. [12] found that the optimal molar ratio of $\mathrm{SiO}_{2}: \mathrm{Al}_{2} \mathrm{O}_{3}: \mathrm{Na}_{2} \mathrm{O}: \mathrm{NaOH}: \mathrm{H}_{2} \mathrm{O}$ for metakaolinbased GB should be 3.4:1.1:0.5:1.0:11.8. Traa and Thompson [13] and Yip et al. [14] found that the aluminosilicate sources were more likely to produce $\mathrm{Na}$-A zeolite with good crystallinity under low-concentrated alkali solution $\left[\mathrm{m}\left(\mathrm{H}_{2} \mathrm{O}\right) / \mathrm{M}\left(\mathrm{Na}_{2} \mathrm{O}\right) \approx 26\right]$ but amorphous aluminosilicate gels with network structure under high-concentrated alkali solution $\left[\mathrm{m}\left(\mathrm{H}_{2} \mathrm{O}\right) / \mathrm{M}\left(\mathrm{Na}_{2} \mathrm{O}\right) \approx 11\right]$. Yang et al. [15] further indicated that the aluminosilicate sources would be quickly dissolved into supersaturated $\mathrm{SiO}_{4}{ }^{4-}$ and $\mathrm{AlO}_{4}{ }^{5-}$ ions in a strong-alkaline reaction environment but accompanied by difficulties in the growth of crystals since the massive nucleus of Na-A zeolite would vie with each other; on the contrary, Na-A zeolite was much easier to form in a weak-alkaline reaction environment. Bayuaji et al. [16] summarized the preparation of dry-mixed GB.

Various studies have employed GB to enhance the properties of problematic soils. Brand et al. [17] found that the unconfined compressive strength (UCS) and dynamic modulus of clayey soil, relative to the untreated case, could be increased by 91 and $221 \%$ when $15 \%$ of ladle metallurgy furnace (LMF) slag was used. Jiang et al. [18] studied the effects of rice husk ash (RHA) on silty clay (SC) stabilization and reported that the optimum dosage of RHA was 2,4 , and $6 \%$ when the content of $\mathrm{CaO}$ was 3,5 , and $7 \%$, respectively. Zhang et al. [19] found that the UCS of cementstabilized marine soil would be increased by about 2.0-3.0 times after mixing with 3-5\% metakaolin-based GB; Li et al. [20] pointed out that adding $15-20 \%$ of FA could obtain the best strength and deformation resistance of cemented coastal soil.
Wang et al. [21] considered that the best mixing ratio of GB to soft soil was $14 \%$, which led to a rapid increase of strength and a significant reduction of porosity at $20^{\circ} \mathrm{C}$ for 7 days.

Overall, there is no uniform standard for the production of GB up to now, which results in difficulties in large-scale engineering applications directly. In addition, the synthesis of aluminosilicate gels needs a feasible alkali environment. However, the improper use of alkali may cause environmental problems. Therefore, further exploratory research remains to be conducted. This study focused on the material ratio of metakaolin-based GB by employing a relatively weak alkali environment, and the improvement mechanism of this metakaolin-based GB on the SC. The optimal material ratios of MK, AA [the mixture of $\mathrm{CaO}$ and $\mathrm{NaHCO}_{3}$ (sodium bicarbonate)], and SC were investigated by a series of unconfined compression tests. The stabilization mechanism and microstructural characteristics of the SC before and after the treatment were discussed through $\mathrm{x}$-ray diffraction (XRD), Fourier transform infrared spectroscopy (FTIR), scanning electron microscopy (SEM) with an energy dispersive $\mathrm{x}$-ray (EDX) spectroscopy, and mercury intrusion porosimetry (MIP), respectively.

\section{MATERIALS AND METHODS}

\section{Experimental Materials}

\section{1) Soil}

The SC sample used in this study was collected from a construction site on the Jiangpu Campus of Nanjing Tech University, China, and air-dried and sieved to obtain particles lower than $2 \mathrm{~mm}$. The dry density of this SC was $1.64 \mathrm{~g} / \mathrm{cm}^{3}$. Its optimum moisture content (OMC) and maximum dry density $\left(\gamma_{\text {dmax }}\right)$ were $18.2 \%$ and $1.72 \mathrm{~g} / \mathrm{cm}^{3}$. The UCS was $178.8 \mathrm{kPa}$. The internal friction angle and cohesion were $24.5^{\circ}$ and $26.4 \mathrm{kPa}$, respectively.

\section{2) GB}

The raw material (precursor) of GB was white powdered MK produced by Shengyun Mining Company in Hebei Province, China. The total content of $\mathrm{SiO}_{2}$ and $\mathrm{Al}_{2} \mathrm{O}_{3}$ is greater than $95 \%$. Many studies illustrated that the combination of $\mathrm{NaOH}$ and $\mathrm{Na}_{2} \mathrm{SiO}_{3}$ solutions could be the best choice for the polymerization of aluminosilicate sources [11, 17, 22] because $\mathrm{NaOH}$ could dissolve aluminosilicate sources and $\mathrm{Na}_{2} \mathrm{SiO}_{3}$ continuously, providing more $\mathrm{Na}^{+}$and $\mathrm{Si}^{4+}$ for polymerization. However, great difficulties in the transit and storage of $\mathrm{NaOH}$ and $\mathrm{Na}_{2} \mathrm{SiO}_{3}$ solutions and ecological environment protection are always likely to be encountered in engineering practices. The polymerization of aluminosilicate sources must adopt a more rational way to create the reaction environment that not only meets the demand in practical cases but also has relatively low environmental footprints. The $\mathrm{CaO}$ and $\mathrm{NaHCO}_{3}$ can react in water to form an alkaline solution by 
$\left\{\mathrm{CaO}+2 \mathrm{NaHCO}_{3}+\mathrm{H}_{2} \mathrm{O} \rightarrow \mathrm{CaCO}_{3} \downarrow+\mathrm{Na}_{2} \mathrm{CO}_{3}+2 \mathrm{H}_{2} \mathrm{O}, \quad \mathrm{NaHCO}_{3}\right.$ is excessive $\left\{\mathrm{CaO}+\mathrm{NaHCO}_{3}+\mathrm{H}_{2} \mathrm{O} \rightarrow \mathrm{CaCO}_{3} \downarrow+\mathrm{NaOH}+\mathrm{H}_{2} \mathrm{O}, \quad \mathrm{CaO}\right.$ is excessive

Dry powers of $\mathrm{CaO}$ and $\mathrm{NaHCO}_{3}$ can bring great convenience for transit and storage and reduce environmental footprints effectively. Hence, it is a viable option to select the dry powder mixture of $\mathrm{CaO}$ and $\mathrm{NaHCO}_{3}$ as AA. Theoretically, the ideal mole ratio of $\mathrm{CaO}$ and $\mathrm{NaHCO}_{3}$ should be 1:1, corresponding to a mass ratio of $56: 84$. However, to ensure the reaction requirements and for the sake of practical convenience, the excessive usage of $\mathrm{CaO}$ is more appropriate. Here, the mass ratio of $\mathrm{CaO}$ and $\mathrm{NaHCO}_{3}$ was set to be $1: 1$, which, on the one hand, could guarantee the reaction of $\mathrm{CaO}$ and $\mathrm{NaHCO}_{3}$ to produce $\mathrm{NaOH}$ effectively and, on the other hand, could control the impact of dry shrinkage and crack induced by $\mathrm{Ca}(\mathrm{OH})_{2}$ on the mechanical performance of SC within an acceptable level. The samples of $\mathrm{CaO}$ and $\mathrm{NaHCO}_{3}$ used in this study were white chemically pure powder collected from the State Key Laboratory of Materials-Oriented Chemical Engineering at Nanjing Tech University.

\section{Experimental Schemes UCT}

By referring to documented literature about GB with different raw materials and alkali-activated conditions, the geopolymerstabilized SC (GSC) samples with MK of $6,8,10$, and 12\%, and AA of $3,5,7,9$, and $11 \%$, as the initial material ratios, were prepared for investigating the optimal mass mixing ratio (MMR) of MK and AA first, and then GSC samples with 3, 5, 8, 10, 12, 15, and $20 \%$ of GB (the mixture of MK and AA with the obtained optimal MMR) were prepared to find the optimal MMR of AA, MK, and SC. Considering that the formation of alkali environments for polymerization was determined by the hydration of $\mathrm{CaO}$ and the reaction of $\mathrm{CaO}$ and $\mathrm{NaHCO}_{3}$ in water and that these reactions would start rapidly at the early curing age, the curing time was selected to be 1 day, 3 days, and 7 days to facilitate tracing changes in the crystallographic structure of aluminosilicate and the microstructural characteristics of GSC. A YSH-2 Unconfined Compression device implemented the UCT at a $1 \mathrm{~mm} / \mathrm{min}$ strain rate. Three parallel samples were prepared at least for each mixing ratio.

\section{XRD/FTIR}

Single-phase $\mathrm{x}$-ray diffraction patterns and infrared absorption bands of GSC with the optimal MMR of AA, MK, and SC were measured after curing for 1 day, 3 days, and 7 days. The XRD mineralogical composition data over the scattering $2 \theta$ angle range $5^{\circ}-80^{\circ}(2 \mathrm{~h})$ were obtained using a SmartLabTM-3kW with Co Ka radiation, operated at $40 \mathrm{kV}$ and $30 \mathrm{~mA}$, with a step size of $0.02^{\circ}$ and count time of $10 \mathrm{~s} / \mathrm{step}$ at $25^{\circ} \mathrm{C}$. The FTIR transmittance spectra information of finely ground samples were collected by a Nicolet iS20 FTIR Spectrometer in the absorbance mode from 400 to $4,000 \mathrm{~cm}^{-1}$ at a resolution of $0.25 \mathrm{~cm}^{-1}$ and 64 scans per spectrum. A region of interest was defined on each sample as a square $30 \times 30$ points in size, on $10 \mu \mathrm{m}$ grid spacing and $20 \mu \mathrm{m} \times$ $20 \mu \mathrm{m}$ aperture size.

\section{SEM-EDX/MIP}

The microscopic examination by SEM (JSM-6510) with an EDX device (NS7-7911) was performed to observe the internal structural change of GSC samples with the optimal MMR of AA, MK, and SC after curing for 1 day, 3 days, and 7 days. Small dried specimens were trimmed flat in the thickness of approximately $5 \mathrm{~mm}$ first and then vacuumed with a gold layer for SEM-EDX to make it electrically conductive to prevent electric charge on the specimens. The main elements taken into account for the EDX spectra analysis were $\mathrm{Si}$ and $\mathrm{Al}$. The pore distribution characteristics of clay and GSC samples were evaluated by MIP test (Quantchrome PM60GT-18, United States) in which a low pressure of about $6-180 \mathrm{kPa}$ was utilized first to evacuate gases, fill the sample holder with mercury, and perform porosimetry, and then a high pressure between $420 \mathrm{kPa}$ and $207 \mathrm{MPa}$ was applied again. The contact angle and surface tension assumed for all tests were $117^{\circ}$ and $485 \mathrm{dyn} / \mathrm{cm}$, respectively.

\section{Specimen Preparation}

The dry SC samples were mixed with GB thoroughly and then blended with a specific water dosage multiple times. The water consumption was determined by the OMC of SC and an additional fixed water/GB ratio of 0.35 . Namely, the amount of water for sample preparation was the sum of the water corresponding to ensure SC achieving the maximum compactness and the water vying with the content of GB. A specimen preparation device's inner surface with a diameter of $39.1 \mathrm{~mm}$ and height of $80.0 \mathrm{~mm}$ was daubed with Vaseline. Then, the wet GSC samples were filled into the preparation device four times. Each part of the wet GSC samples was compacted evenly until the compacted height reached the target values, and the surface of each layer was roughened for good interconnection. After preparation, these specimens were numbered and stood in a humidity curing box for $24 \mathrm{~h}$ at ambient temperature and then continually cured for 6 days at the same conditions.

\section{RESULTS AND DISCUSSION}

\section{Mixing Ratio Analysis}

Figures 1A,B show the UCS of GSC specimens with different contents of AA and MK. It can be observed that the UCS of GSC specimens increases first and then decreases with the increasing contents of $\mathrm{AA}$ and $\mathrm{MK}$ as a whole. The GSC specimens containing $5 \%$ of $\mathrm{AA}$ and $10 \%$ of $\mathrm{MK}$ obtained the maximum 7 -day UCS. Its mean value was $418.63 \mathrm{kPa}$. The reason for these changes may be if the amount of AA exceeds the polymerization demand of $\mathrm{MK}$, the limited amount of sodium or calcium aluminosilicate gels cannot improve the strength performance of SC effectively, while the residual $\mathrm{Ca}(\mathrm{OH})_{2}$ (the main hydration products of $\mathrm{CaO}$ ) may harm the inner structure of GSC due to dry shrinkage and crack, thereby leading to strength reduction; if the amount of $\mathrm{MK}$ is overmuch, the weak alkalinity created by the hydration of $\mathrm{CaO}$ and the reaction of $\mathrm{Ca}(\mathrm{OH})_{2}$ and $\mathrm{Na}_{2} \mathrm{SiO}_{3}$ may result in a poor polymerization response, a low synthetic rate of 

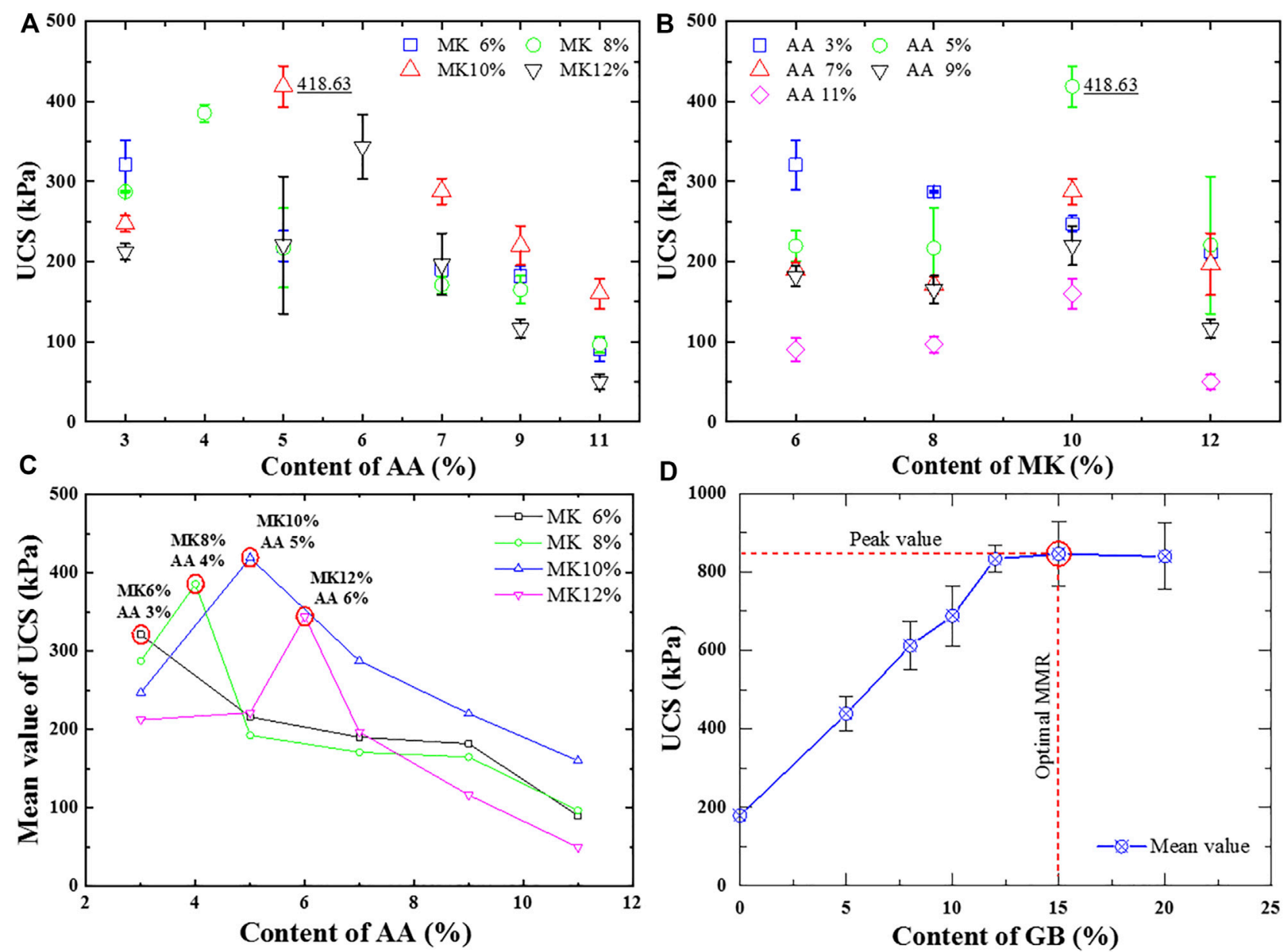

FIGURE 1 | The UCS of GSC specimens with different mixing ratios of GB.

aluminosilicate gels, and a large surplus of MK. Hence, higher ratios of AA and MK do not bring better polymerization. There should be an optimum mixing ratio between AA and MK.

Figure 1C presents the mean UCS of GSC specimens with different contents of AA and MK. It can be seen that the UCS of GSC specimens with the same content of MK takes on characteristics of increasing first and then decreasing as a whole, except for the case of GSC specimens with the content of MK as $6 \%$. This is because the ratios of MK and AA greater than 2:1 were not considered in the cases of the content of $\mathrm{MK}$ as $6 \%$. Remarkably, the UCS of GSC specimens with the same content of MK always reaches their peak values when the content of MK is precisely twice that of AA. Therefore, it can be concluded that the ideal MMR of AA and MK should be 1:2.

Figure 1D illustrates the UCS of GSC specimens with different contents of GB. The MMR of AA and MK to prepare GB was 1:2. Results indicate that the UCS of GSC specimens increases first and then slightly decreases with the content of GB as a whole. When the content of GB is less than $12 \%$, the UCS of GSC specimens approximately grows linearly. When the content of GB is greater than $12 \%$, this growth trend slows rapidly. The UCS of GSC specimens reaches the maximum value when the content of
GB increases to $15 \%$. However, when the content of GB is higher than $15 \%$, the UCS does not increase anymore but slightly decreases. One reason for this change is that the mass mixing ratio of $\mathrm{CaO}$ and $\mathrm{NaHCO}_{3}$ used in this study was 1:1. The content of $\mathrm{CaO}$ in such a situation is overmuch for the reaction of $\mathrm{CaO}$ and $\mathrm{NaHCO}_{3}$ in water. With the increase of GB content, the relative content of $\mathrm{CaO}$ in GSC specimens increases proportionately. The hydration of these excess $\mathrm{CaO}$ will produce much more $\mathrm{Ca}(\mathrm{OH})_{2}$, resulting in dry shrinkage and crack in SC in local [23]. The other reason is that the water consumption for sample preparation is the sum of the water corresponding to ensure that SC achieves the maximum compactness and the water vying with the content of $\mathrm{GB}$ proportionally. The more GB added requires more water mixed in GSC specimens. Once aluminosilicate gels' contributions on the strength improvement of SC are relatively lower than that of excess water-consuming decreased, a strength reduction will occur inevitably. On the whole, the optimal MMR of GB for SC stabilization should be $15 \%$. Of course, in terms of economics, the mixing ratio of $12 \%$ could be more acceptable if the performance of GSC meets the strength requirement of engineering practices. According to the 

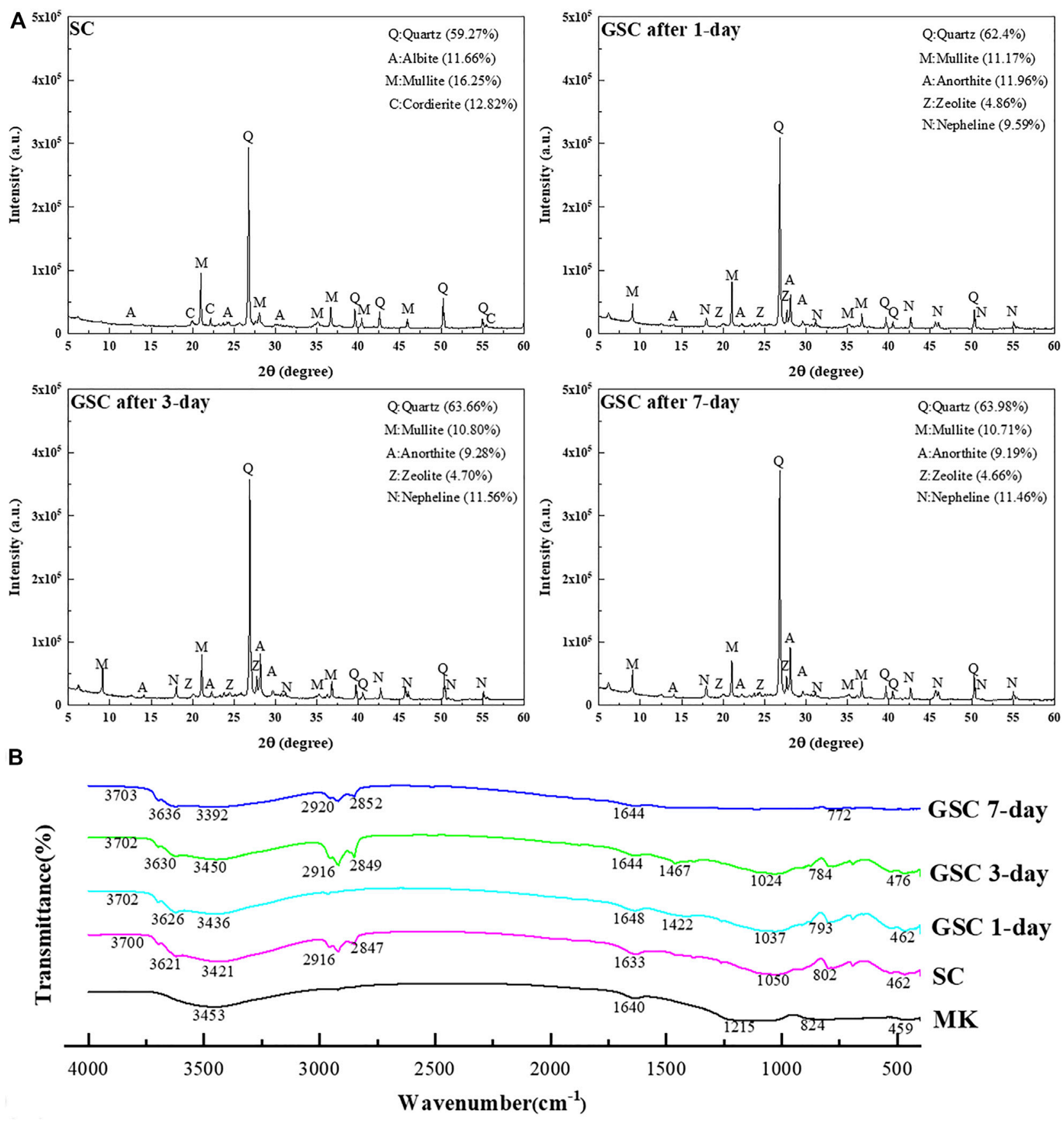

FIGURE 2 | XRD pattern and FTIR spectra of SC and GSC specimens after 1 day, 3 days, and 7 days.

previously obtained MMR about AA and MK, the optimal MMR of AA, MK, and SC should be 1:2:17.

\section{Stabilization Mechanisms}

The crystallographic structure of aluminosilicate sources will change in a strong alkali environment over time [24]. Figure 2A shows the $\mathrm{x}$-ray diffraction pattern over the angular range of $5^{\circ}-60^{\circ}(2 \theta)$ for GSC with $15 \%$ of GB after
1 day, 3 days, and 7 days. Compared with the crystalline peak intensity of SC, the most significant changes are mainly related to the angular range of $15^{\circ}-45^{\circ}$ with the center approximately $2 \theta \approx 27^{\circ}$. The ubiquitous quartz is always the most dominant mineral in GSC and has broad diffraction peaks. The crystalline peaks of quartz, anorthite, and zeolite are increasing with the curing ages. Namely, the longer the curing age is, the higher their crystalline peaks are. The 

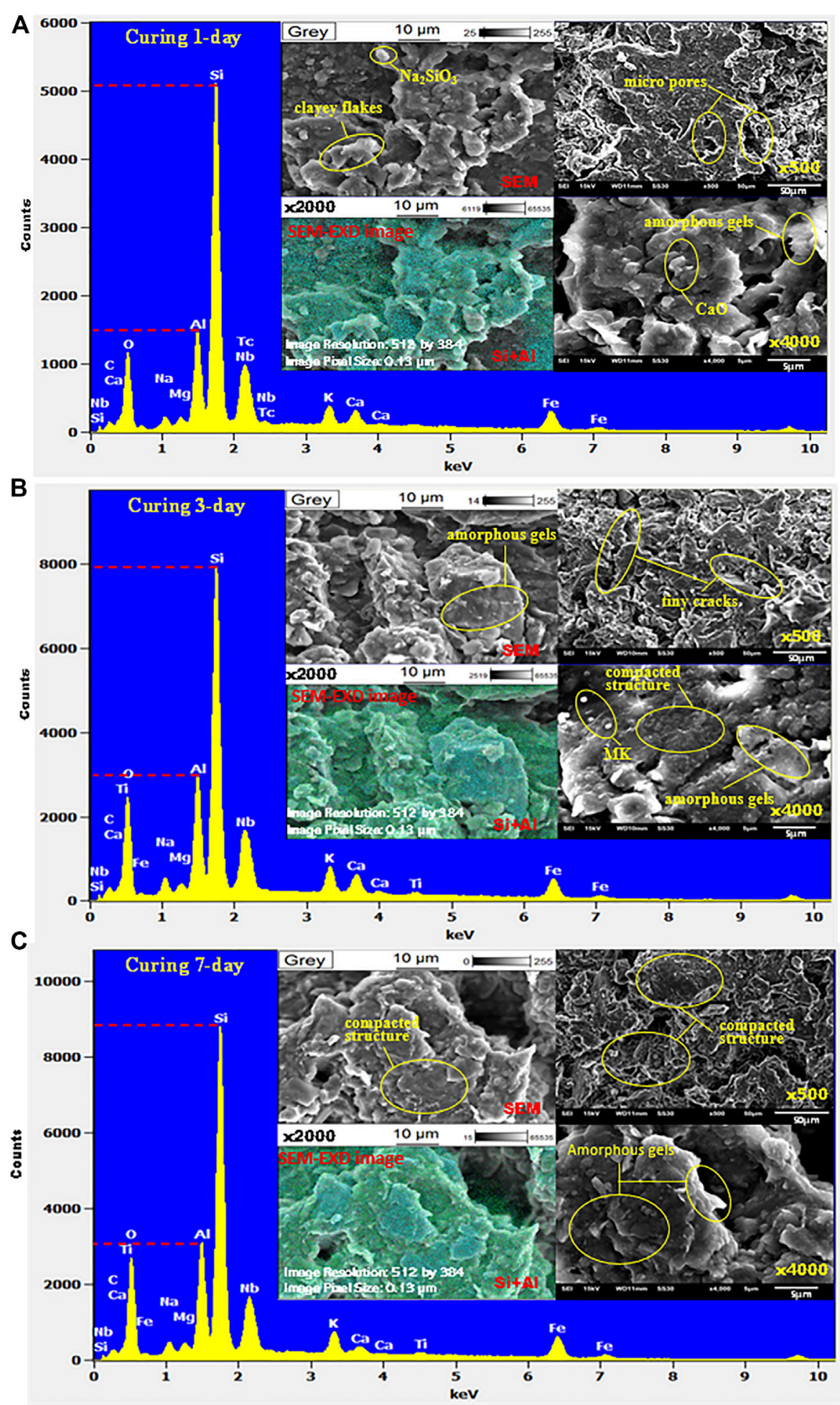

FIGURE 3 | SEM images and EDX analyses of GSC specimens after 1 day, 3 days, and 7 days.

peak intensity reduction of minerals (mullite) in the SC is changing in the angular range of $20^{\circ}-35^{\circ}(2 \theta)$, which is the typical diffraction range of calcium aluminum silicate hydrates (CASH). Thus, both calcium silicate hydrates (CSH) and calcium aluminate hydrates $(\mathrm{CAH})$ derived from $\mathrm{CASH}$ are being generated in GSC. These highlighted new peaks demonstrate that the practical addition of GB has caused positive results. 

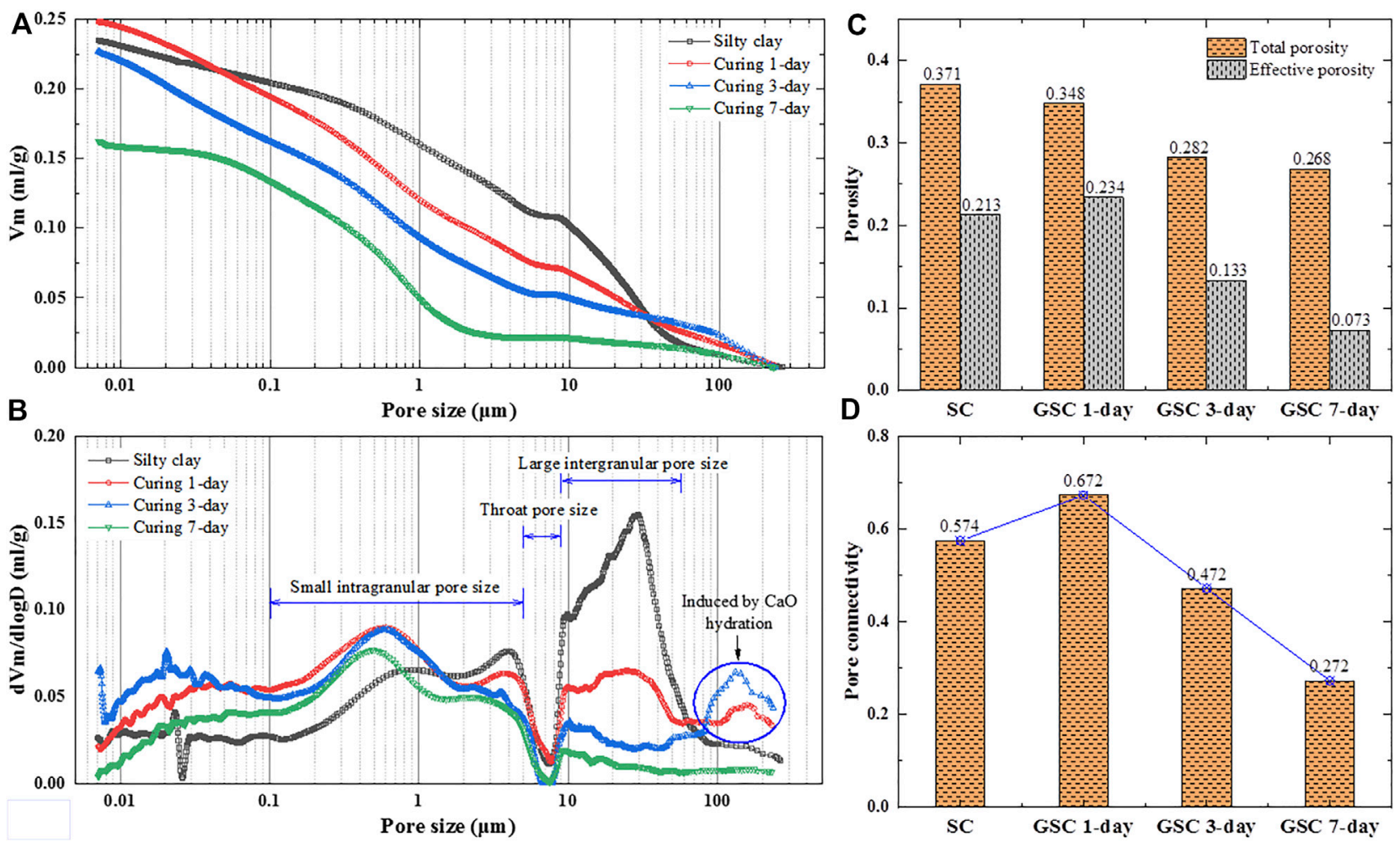

FIGURE 4 | Pore structure characteristics of SC and GSC after curing for 1 day, 3 days, and 7 days.

FTIR spectroscopy can monitor polymerization reaction and evaluate the asymmetric stretching vibration of Si-O-Al linkages by band absorbance ranging $1,300-900 \mathrm{~cm}^{-1}$ [25]. Other major bands were attributed to the stretching (approximately $3,450 \mathrm{~cm}^{-1}$ ) and bending (approximately $1,650 \mathrm{~cm}^{-1}$ ) vibration of absorbed $\mathrm{H}_{2} \mathrm{O}$ [12]. Some studies pointed out that the bands at approximately $600-450 \mathrm{~cm}^{-1}$ were due to $\mathrm{Si}-\mathrm{O}-\mathrm{Si}, \mathrm{Al}-\mathrm{O}-\mathrm{Si}$, and $\mathrm{O}-\mathrm{Si}-\mathrm{O}$ bending vibrations $[26,27]$. Figure 2B illustrates the FTIR transmittance spectra of GSC after curing for 1 day, 3 days, and 7 days. It can be found that the strong asymmetrical stretching vibration peak of Si-O and Al-O bonds at approximately $1,215 \mathrm{~cm}^{-1}$ in the MK spectrum had shifted to a lower wavenumber at $1,010 \mathrm{~cm}^{-1}$ as the curing ages developed. This change indicates that the solidification of GSC was evolving along with the formation of a new substance. The bands at $1,094-1,033 \mathrm{~cm}^{-1}$ associated with the asymmetric stretching mode of original MK were found in all spectra, which implied that a part of unreacted MK remains in GSC. The bands at $824 \mathrm{~cm}^{-1}$ in the spectrum of MK diminish during polymerization and expose the high heterogeneity in the structural evolution of amorphous aluminosilicates. A new peak at approximately $772 \mathrm{~cm}^{-1}$ that denoted the bending vibration of tetra-coordinated $\mathrm{Si}-\mathrm{O}-\mathrm{Al}$ in a chain structure was observed on the FTIR spectra of GSC, which signified the formation of aluminosilicate networks and should be responsible for the strength improvement of SC.

\section{Microstructural Characteristics}

SEM and EDX techniques were applied to observe the microstructural characteristics of GSC with $15 \%$ of GB after curing for 1 day, 3 days, and 7 days, as shown in Figure 3. SEM images show that the loose flaky units of SC have been wrapped and connected by unoriented gels as the curing age develops. The previous independent tiny particles, aggregates, and flocs have formed into super aggregates with strong network links. The arrangement between super aggregates and cementitious flocs becomes compacted along with a more homogeneous microstructure. The overhead phenomenon reduces dramatically. All these microstructural evolutions demonstrate that the aluminosilicate gels produced by $\mathrm{GB}$ were filling into the pores in the SC to make its structure more compacted and connecting silty particles and clayey flakes to super aggregates with strong network links. These inner changes would restrict the local relative slip among soil particles when they were subjected to external loadings so that the mechanical performance of the SC appears to be improved at the macro scale. EDX results indicate that the counts of $\mathrm{Si}$ and $\mathrm{Al}$ components in GSC were increasing over the curing age. After curing for 7 days, the initial counts of the $\mathrm{Al}$ component increased from about 1,500 to 3,200 , and the initial counts of the $\mathrm{Si}$ component increased from about 5,200 to 8,800 . These changes implied that more aluminosilicate gels were just forming over the curing age. The changes of $\mathrm{Si}$ and $\mathrm{Al}$ components could also be observed in SEM-EDX images, in 
which the distribution of green and cyan points denoting the $\mathrm{Si}$ and $\mathrm{Al}$ components was becoming denser and denser over the curing age. Namely, the polymerization of GB was in progress.

Microstructure characteristics of SC and GSC samples after curing for 1 day, 3 days, and 7 days were investigated by MIP tests, including pore size, pore distribution, total porosity, effective porosity, and pore connectivity, as shown in Figure 4. It can be observed that the SC samples have a large intergranular pore size at $8-50 \mu \mathrm{m}$ and a small intragranular pore size concentrated at $0.2-6.0 \mu \mathrm{m}$ in diameter $(D)$. When the GB was added to the SC, the proportion of large pore volume in SC samples decreased, and the proportion of small pore volume is quite the opposite (Figures 4A,B). The curves of the accumulative mercury intrusion volume per gram soils $\left(V_{\mathrm{m}}\right)$ and the differential intrusion volume versus the entrance pore diameter of GSC samples illustrate that the large pore size is similarly concentrated at $8-50 \mu \mathrm{m}$ while the small pore size is concentrated at $0.1-2 \mu \mathrm{m}$ in diameter. The pore volume of GSC samples at $80-200 \mu \mathrm{m}$ in pore diameter increases first and then decreases at the early curing age. It may be due to the hydration of $\mathrm{CaO}$ at the early curing age, which results in many air pores in GSC samples despite being treated at ambient temperature. Overall, the proportion of large pore volume in GSC decreases with the curing age but is accompanied by a continuously increasing small pore volume. The pore sizes decrease with the curing age, and the pore size distribution shifts towards smaller pore sizes. SEM images can explain this change in that the reaction products of GB are gradually filling the pores in GSC with curing age, thereby reducing pore size and volume. Figures 4C,D show the variations of porosity and pore connectivity of SC and GSC samples with the curing age. It can be found that GB can positively make the structure of SC compact in the early curing age. The total porosity of GSC samples decreases continuously over the curing age but has a slow rate of decline at the later curing age. The pore connectivity of SC and GSC samples increases first and then decreases with the curing age. The reduced porosity and the refined microstructure indicate that a higher reaction degree of GB at the later curing age leads to more reaction products, filling the pore space and resulting in a denser microstructure of SC. These variations should be responsible for rapidly forming the robust structure of GSC at the later curing age.

\section{CONCLUSION}

Utilizing new soil stabilization alternatives, such as synthetic polymers, copolymer-based products, or cross-linking styreneacrylic polymers, can change a natural soil to meet an engineering

\section{REFERENCES}

1. Furlan AP, Razakamanantsoa A, Ranaivomanana H, Amiri O, Levacher D, Deneele D. Effect of Fly Ash on Microstructural and Resistance Characteristics of Dredged Sediment Stabilized with Lime and Cement. Construction Building Mater (2021) 272:121637. doi:10.1016/j.conbuildmat.2020.121637 purpose in an environmentally friendly and effective way. The feasibility of metakaolin-based geopolymer employing the mixture of $\mathrm{CaO}$ and $\mathrm{NaHCO}_{3}$ as an AA has been confirmed as an effective soil stabilizer. Some main conclusions were highlighted as follows: 1) The UCS of GSC specimens increases first and then decreases with both $\mathrm{AA}$ and $\mathrm{MK}$ contents. The maximum UCS of GSC could reach $0.85 \mathrm{MPa}$ when adding $15 \mathrm{wt} \%$ of GB with an optimal MMR of AA:MK: SC as 1:2:17. 2) XRD patterns and FTIR spectra indicate that the addition of GB could cause positive results in the formation of geopolymer gels, realizing effective SC stabilization. The structural evolution of amorphous aluminosilicates over curing ages is responsible for soil strength improvement. 3) The microstructural observation further qualitatively confirmed the formation of geopolymer gels in GSC. The mechanical performance improvement of untreated SC should be due to the effect of polymeric bonds and the increase in the homogeneity of GSC specimens. The results of this study can provide a reference to the application of GB in soil stabilization.

\section{DATA AVAILABILITY STATEMENT}

The original contributions presented in the study are included in the article/Supplementary Material, further inquiries can be directed to the corresponding authors.

\section{AUTHOR CONTRIBUTIONS}

Funding acquisition and formal writing of the work, SW; investigation and data analysis of the work, JS and $\mathrm{HH}$; review and editing of the work, ZW, WM, and YL. All authors have read and agreed to the published version of the manuscript.

\section{FUNDING}

National Natural Science Foundation of China (Grant No. 41902282) Natural Science Foundation of Jiangsu Province (Grant No. BK20171006) State Key Laboratory of Frozen Soil Engineering (Grant No. SKLFSE201809).

\section{SUPPLEMENTARY MATERIAL}

The Supplementary Material for this article can be found online at: https:/www.frontiersin.org/articles/10.3389/fphy.2021.769786/ full\#supplementary-material

2. Pan C, Xie X, Gen J, Wang W. Effect of Stabilization/solidification on Mechanical and Phase Characteristics of Organic River silt by a Stabilizer. Construction Building Mater (2020) 236:117538. doi:10.1016/ j.conbuildmat.2019.117538

3. Kamaruddin FA, Nahazanan H, Kim Huat B, Anggraini V. Improvement of Marine Clay Soil Using Lime and Alkaline Activation Stabilized with Inclusion of Treated Coir Fibre. Appl Sci (2020) 10(6):2129. doi:10.3390/app10062129 
4. Liu L, Zhou A, Deng Y, Cui Y, Yu Z, Yu C. Strength Performance of Cement/ slag-Based Stabilized Soft Clays. Construction Building Mater (2019) 211: 909-18. doi:10.1016/j.conbuildmat.2019.03.256

5. Gaspard K, Zhang Z. Assessment of Shrinkage Crack Mitigation Technique Performance in Soil Cement Base Courses. In: Transportation Research Board Meeting. Washington DC, United States: The National Academies of Sciences, Engineering, and Medicine (2009).

6. Nawaz M, Heitor A, Sivakumar M. Geopolymers in Construction - Recent Developments. Construction Building Mater (2020) 260:120472. doi:10.1016/ j.conbuildmat.2020.120472

7. Pelisser F, Guerrino EL, Menger M, Michel MD, Labrincha JA. Micromechanical Characterization of Metakaolin-Based Geopolymers. Construction Building Mater (2013) 49:547-53. doi:10.1016/ j.conbuildmat.2013.08.081

8. Wu Y, Lu B, Bai T, Wang H, Du F, Zhang Y, et al. Geopolymer, green Alkali Activated Cementitious Material: Synthesis, Applications and Challenges. Construction Building Mater (2019) 224:930-49. doi:10.1016/ j.conbuildmat.2019.07.112

9. Garcia-Lodeiro I, Palomo A, Fernández-Jiménez A. An Overview of the Chemistry of Alkali-Activated Cement-Based Binders. In: Handbook of Alkali-Activated Cements, Mortars and Concretes. Elsevier (2015). p. 19-47. doi:10.1533/9781782422884.1.19

10. Rios S, Cristelo N, Viana Da Fonseca A, Ferreira C. Structural Performance of Alkali-Activated Soil Ash versus Soil Cement. J Mater Civil Eng (2016) 28(2): 4015125. doi:10.1061/(ASCE)MT.1943-5533.0001398

11. Farhan KZ, Johari MAM, Demirboğa R. Assessment of Important Parameters Involved in the Synthesis of Geopolymer Composites: A Review. Construction Building Mater (2020) 264:120276. doi:10.1016/j.conbuildmat.2020.120276

12. Chen L, Wang Z, Wang Y, Feng J. Preparation and Properties of Alkali Activated Metakaolin-Based Geopolymer. Materials (2016) 9(9):767. doi:10.3390/ma9090767

13. Traa Y, Thompson RW. Controlled Co-crystallization of Zeolites A and X. J Mater Chem (2002) 12(3):496-9. doi:10.1039/b108634k

14. Yip CK, Provis JL, Lukey GC, van Deventer JSJ. Carbonate mineral Addition to Metakaolin-Based Geopolymers. Cement and Concrete Composites (2008) 30(10):979-85. doi:10.1016/j.cemconcomp.2008.07.004

15. Yang T, Yao X, Zhang Z, Zhu H. Effects of $\mathrm{NaOH}$ Solution Concentration and Reaction Time on Metakaolin Geopolymerization. J Nanjing Univ Tech (Natural Sci Edition) (2013) 35(4):21-5. doi:10.3969/j.issn.16717627.2013.04.005

16. Bayuaji R, Yasin AK, Susanto TE, Darmawan MS. A Review in Geopolymer Binder with Dry Mixing Method (Geopolymer Cement). In: Proceedings of the Green Construction and Engineering Education (GCEE) Conference. East Java, Indonesia: AIP Publishing (2017) doi:10.1063/1.5003505

17. Brand AS, Singhvi P, Fanijo EO, Tutumluer E. Stabilization of a Clayey Soil with Ladle Metallurgy Furnace Slag Fines. Materials (2020) 13(19):4251. doi:10.3390/ma13194251

18. Jiang X, Huang Z, Ma F, Luo X. Analysis of Strength Development and SoilWater Characteristics of Rice Husk Ash-Lime Stabilized Soft Soil. Materials (2019) 12(23):3873. doi:10.3390/ma12233873

19. Zhang T, Yue X, Deng Y, Zhang D, Liu S. Mechanical Behaviour and Microstructure of Cement-Stabilised marine clay with a Metakaolin Agent.
Construction Building Mater (2014) 73:51-7. doi:10.1016/ j.conbuildmat.2014.09.041

20. Li N, Zhu Q, Wang W, Song F, An D, Yan H. Compression Characteristics and Microscopic Mechanism of Coastal Soil Modified with Cement and Fly Ash. Materials (2019) 12(19):3182. doi:10.3390/ma12193182

21. Wang H, Yao J, Lin Y, He H. Research of Geopolymer Deal with the Strength of Soft Soil and Microstructure Test. In: S Shu, L He, Y Kai, editors. New Developments in Materials for Infrastructure Sustainability and the Contemporary Issues in Geo-Environmental Engineering. Cham: Springer International Publishing (2019) p. 204-14. doi:10.1007/978-3-319-95774-6_16

22. Shubbar AA, Sadique M, Kot P, Atherton W. Future of clay-based Construction Materials - A Review. Construction Building Mater (2019) 210:172-87. doi:10.1016/j.conbuildmat.2019.03.206

23. Dash SK, Hussain M. Influence of Lime on Shrinkage Behavior of Soils. J Mater Civil Eng (2015) 27(12):4015041. doi:10.1061/(asce)mt.19435533.0001301

24. Juengsuwattananon K, Winnefeld F, Chindaprasirt P, Pimraksa K. Correlation between Initial $\mathrm{SiO} 2 / \mathrm{Al} 2 \mathrm{O} 3, \mathrm{Na} 2 \mathrm{O} / \mathrm{Al} 2 \mathrm{O} 3, \mathrm{Na} 2 \mathrm{O} / \mathrm{SiO} 2$ and $\mathrm{H} 2 \mathrm{O} / \mathrm{Na} 2 \mathrm{O}$ Ratios on Phase and Microstructure of Reaction Products of Metakaolinrice Husk Ash Geopolymer. Construction Building Mater (2019) 226:406-17. doi:10.1016/j.conbuildmat.2019.07.146

25. Rovnaník P. Effect of Curing Temperature on the Development of Hard Structure of Metakaolin-Based Geopolymer. Construction Building Mater (2010) 24(7):1176-83. doi:10.1016/j.conbuildmat.2009.12.023

26. Puligilla S. Understanding the Role of Slag on Geopolymer Hardening and Microstructural Development. Urbana, Illinois: University of Illinois at Urbana-Champaign (2011).

27. Vinai R, Panagiotopoulou C, Soutsos M, Taxiarchou M, Zervaki M, Valcke S, et al. Sustainable Binders for concrete: A Structured Approach from Waste Screening to Binder Composition Development. Heron (2015) 60(1/2):27-57.

Conflicts of Interest: Author YL is employed by the State Key Laboratory of Safety and Health for Metal Mines, Sinosteel Maanshan Institute of Mining Research Co., LTD.

The remaining authors declare that the research was conducted in the absence of any commercial or financial relationships that could be construed as a potential conflict of interest.

Publisher's Note: All claims expressed in this article are solely those of the authors and do not necessarily represent those of their affiliated organizations, or those of the publisher, the editors and the reviewers. Any product that may be evaluated in this article, or claim that may be made by its manufacturer, is not guaranteed or endorsed by the publisher.

Copyright (C) 2021 Wang, Su, Wu, Ma, Li and Hui. This is an open-access article distributed under the terms of the Creative Commons Attribution License (CC BY). The use, distribution or reproduction in other forums is permitted, provided the original author(s) and the copyright owner(s) are credited and that the original publication in this journal is cited, in accordance with accepted academic practice. No use, distribution or reproduction is permitted which does not comply with these terms. 